\title{
DAS ARTES LIBERAIS À FILOSOFIA NAS UNIVERSIDADES MEDIEVAIS
}

Scott Randall Paine"

SIINTESE - O presente ensaio não se entende como uma pesquisa crítico-histórica das artes liberais e do seu papel nas universidades medievais, mas antes como uma reflexão filosófica sobre a lógica intrínseca destas artes e a sua interação com a filosofia aristotélica.
ABSTRACT - The present essay isn't a critical/historical investigation about the liberal arts and their role in the universities of the Middle Ages, but rather a philosophical reflection on the intrinsic logic of the quoted arts and their interaction with Aristotle's philosophy.

No artigo que se segue, vão ser empregados os recursos expressivos da Língua Portuguesa, vai ser apresentada e defendida a lógica dum argumento - ou pelo menos, uma hipótese de interpretação que exige uma articulação racional - e vão ser utilizados certos expedientes (ilustrações, apelos aos tópicos atuais, etc.) para agilizar a compreensão, da parte dos leitores, dos assuntos tratados. Costumamos agrupar esses três círculos de tarefas sob a tríplice designação de "gramática", "lógica" e "retórica".

Preparando este artigo, tive que contar as páginas, para ficar dentro dos parâmetros de uma revista. Tive mesmo que levar em conta o tamanho da superfície das páginas, para estimar o quanto eu poderia ampliar o meu desenvolvimento dos temas tratados. A publicação desta revista está prevista para um certo mês do ano, o mês mesmo sendo determinado pela posição do sol na abóbada celeste. Finalmente, a colocação do meu artigo aqui num lugar determinado da revista obedecia - podemos supor - ao desejo da redação de manter um certo ritmo entre as diversas contribuições, criando, enquanto possivel, um diálogo coerente (uma certa melodia, se quiser, unificada por diversos temas e tons respeitantes à filosofia medieval) e assim estabelecer uma harmonia no conjunto deste número da revista.

A forma original deste artigo foi ministrada como conferência na III Semana de Estudos Medievais na Universidade de Brasília, em outubro, 1996. Esta revisão se dirige aos leitores de uma cultura mais filosófica.

" Universidade de Brasília. 
Então, contar paginas é fazer aritmética; estimar dimensões espaciais é fazer geometria; a determinação dos meses durante 0 ano exige astronomia; e unificar os movimentos de uma multidão de coisas - de quaisquer coisas - segundo um certo ritmo e visando uma certa harmonia, é um tipo de música. Como no emprego das palavras para comunicar as minhas idéias, eu aproveitei espontaneamente a Gramática, a Lógica e a Retórica - na mesma forma, e com a mesma espontaneidade, para situar as minhas letras numa página, e para relacionarmos o meu artigo aos demais desta revista, aproveitamos a Aritmética, a Geometria, a Astronomia e a Música.

Ora, estas sete operações básicas de nossa vida cotidiana - cujos traços se poderia identificar em qualquer atividade humana - constituem a matéria estudada nas sete artes que formaram o programa de estudos pré-teológicos (e também pré-jurídicos e pré-médicos) durante a maior parte da Idade Média. Essas artes foram chamadas de artes liberais (artes liberales) por duas razões interrelacionadas: primeiro, por serem as artes características dos homens livres, ou seja, dos homens relativamente libertados dos esforços e do investimento de tempo, requeridos pelo trabalho manual e as suas artes correspondentes, as artes servis (artes serviles); e, em segundo lugar, por serem as artes que desenvolvem e aprofundam os atos mais livres e nobres do espirito humano, aqueles atos que se desempenham, não para alcançar qualquer outro objetivo, mas por causa do valor e da excelência do ato mesmo.

O meu propósito neste artigo será de oferecer só uma primeiríssima abordagem das artes liberais e do seu espírito - se eu puder exprimir-me assim - para ajudar-nos a entender como a Idade Média encarou essas artes e o seu papel na educação. Queremos especialmente perguntar como este papel mudou em vista do surgimento da filosofia aristotélica integral nos séculos XII e XIII. Em que maneira e com que alcance inseriu-se esta problemática dentro da tradição intelectual do Ocidente, mesmo a despeito das múltiplas e insistentes reviravoltas operadas no Renascimento, na Ciência Nova do século XVII, na Ilustração, em relação ao patrimônio medieval?

\section{1 - As artes liberais}

Falando dum modo geral, podemos afirmar que o homem medieval - seja do tempo patrístico (marcado pelas primeiras tentativas de interpretação racional da revelação cristã), seja do tempo de transição entre a era carolíngea e os princípios do século XII (marcado mais pela absorção e transmissão do patrimônio dos gregos e dos Padres cristãos), seja da Alta Escolástica e os seus panoramas intelectuais quase ilimitados - o homem medieval era alguém a quem se tinha passado uma herança imensa, e em muitos aspectos, desordenada e desconhecida. As tribos germânicas que desceram no sul da Europa depois da queda do Império Romano descobriram ali um tesouro cultural que, na sua profundeza e na sua envergadura, ultrapassou, e até intimidou, a sua própria herança.

A filosofia e a arte dos gregos, mesmo imperfeitamente conhecidas, e o Evangelho e a obra teológica dos Padres da Igreja constituíram um conjunto de manuscritos e de tradições que, antes de mais nada, necessitaram organização, classifi- 
cação e, com o tempo, com cada vez mais consciência dos impressionantes novos horizontes dessas obras, comentário. A caraterística, e muitas vezes ridicularizada tendência "sistematizadora" dos medievais, é devida em grande parte a isto. Ora, uma das classificações mais bem sucedidas e influentes era a das sete artes liberais.

Temos que ver este pequeno esquema de sete artes como a cristalização duma doutrina pedagógica remontando pelo menos até Platão.' Platão, mesmo sendo - como ele mesmo insistiu - também um herdeiro duma tradição prévia duma envergadura intelectual (atribuída por ele aos palaioí, os "anciãos"," e por Aristóteles aos pampalaioi ${ }^{3}$ ), podemos supor que qualquer forma destas artes existia desde que o homem começou a articular a sua busca do saber numa maneira racional. Como constatamos no início, as sete atividades que essas artes pretendem dirigir pertencem à nossa vida humana duma maneira inalienável.

Os primeiros autores medievais que davam forma e uma certa interpretação a estas artes eram os chamados "compiladores", começando com Marciano Capela (séc. V) e sua De nuptiis Mercurii et Philologiae; e Santo Agostinho e sua De doctrina christiana; depois, Cassiodoro (VI) e a sua De artibus ac disciplinis liberalium litterarum e, na mesma época, as diversas obras individuais dedicadas a estas artes de Boécio (VI); finalmente, apareceu aquela "Encylopedia Brittanica" da Idade Média, as Etymologiae, de Santo Isidoro de Sevilha.

Esta classificação e resumo duma tradição intelectual já existente presenciamos nesses autores numa maneira altamente pormenorizada, cada arte tendo um eminente auctor da Antigüidade como auctoritas. As fontes da Gramática são Donato (séc. IV) e Prisciano (VI); da Dialética é sobre tudo Aristóteles (nos diversos graus de familiarização com o seu Órganon ao longo dos séculos medievais); da Retórica são Cícero (séc. I a.C.) e Quintilião (séc. I d.C). Nas artes matemáticas, foi a Nicômaco de Gerasa (fins do séc. I) que os aritméticos olhavam; Euclídes (fl. 300 a C.) ficou como o mestre incontestado da Geometria; e Tolomeo (séc. II) era o mesmo na Astronomia. Um clássico na arte de Música não existia na mesma forma como nas outras artes (o nome de Pitágoras era o mais citado, mas existem pouquíssimos textos remontando a ele mesmo, o texto sobre a música de Boécio sendo usado como o texto de preferência).

Assim achamos um sistema de artes que obedecia a uma certa lógica interna na sua transmissão de uma herança antiga. A numeração não era sempre a mesma e diversas artes não constantes em nossa lista foram incluídas por alguns, como, a título de exemplo, a História e a Arquitetura. Mas a correlação bíblica, introduzida por Cassiodoro entre as sete artes e um verso do livro dos Provérbios, ("A Sabedoria edificou sua casa, talhou sete colunas" Pv.9:1), contribuiu para consagrar o setenário como número padrão, convidando comparações ulteriores com os sete Arcanjos, os sete planetas (os cinco planetas visíveis, mais o Sol e a Lua, esses últimos considerados "planetas" segundo o sentido originário no grego: planes = vagabundo, o Sol e a Lua "vagabundeando", juntamente com Mercúrio,

\footnotetext{
ver Republica, 1. VII.

Filebus 16 c, 5-9.

cf. J. Ritter, Aristoteles und die Vorsokratiker, p. 35.
} 
Vênus, Marte, Saturno e Júpiter, contra o pano de fundo dos astros fixos), e as sete virtudes (as três teologais e as quatro morais). Mas eu prefiro, neste contexto, não me apoiar em qualquer vindicação bíblica ou teológica e sim examinar a lógica intrínseca das três artes triviais e das quatro artes quadriviais na sua própria estrutura.

Como já transpareceu nas ligações das sete artes com a nossa experiência comum, elas comportam evidentemente uma divisão em dois grupos: as três artes da linguagem e as quatro artes matemáticas. Comparações com a conhecida divisão das "duas culturas" de C.P. Snow, a arte e a literatura dum lado, e a ciência e a técnica no outro, não seriam totalmente erradas, mas a mente medieval não estava encarando essas coisas segundo os critérios nem de uma cientificidade moderna quanto à Matemática, nem de uma crítica literária moderna quanto às Letras. A divisão derivou mais de uma experiência humana tão simples quanto as percepções pelas quais distinguimos espontaneamente entre qualidade e quantidade, entre "assim" e "quanto", entre um grande homem e um homem grande.

O intelectual medieval entendeu todas as sete artes como justamente artesnão ciências, nem no sentido aristotélico, nem no sentido newtoniano, mas artes. Uma arte é, nesta perspectiva, a recta ratio factibilium, ou seja, uma racionalidade certa, metódica, quanto às coisas que ficam por produzir.

A única diferença entre as artes servis, ou mecânicas, e as liberais, era a natureza do produto que as artes criam: nas artes servis, o produto fica um objeto material (uma cadeira, uma casa, uma boa colheita, etc.), ao passo que nas artes liberais, a "obra" realizada era uma realidade imaterial, ou melhor dizendo, uma realidade lingüística: na Gramática, uma construção sintática ou morfológica; na Lógica, um silogismo; na Retórica, um discurso adaptado às necessidades e situação dos ouvintes, duma certa platéia; na Aritmética, um cálculo; na Geometria, uma medição das dimensões espaciais; na Astronomia, uma previsão dos cursos dos astros; na Música, uma harmonia. Na língua latina, as sete obras eram resumidas pelas palavras: lingua, ratio, tropus, numerus, angulus, astra, tonus.

Estas "obras de arte" eram, para o homem educado da Idade Média, os recursos intelectuais que ele precisava para navegar livremente na sua fé e no seu mundo. E a razão por que ele considerava o exercício destes atos como excelentes em si era por causa da sua ordenação intrínseca a uma "leitura" desta fé e deste mundo, uma leitura cuja suprema meta era nada menos do que a contemplação seja metafísica, seja mística.

Pela leitura "quadrivial" da Natureza, o homem podia meditar, e mais e mais contemplar, o mistério de Deus como cognoscivel através das obras das suas mãos (cf. Salmo 18, e a Carta aos Romanos 1:19). Pela leitura "trivial" da Bíblia, foi visada a contemplação de Deus nas suas obras, digamos, "sobrenaturais", ou seja, a sua intervenção na história humana para redenção e santificação de uma Humanidade desencaminhada.

$\mathrm{Na}$ evolução do pensamento medieval, a interpretação e o uso do trivium e do quadrivium em relação ao conhecimento de Deus, do homem e do mundo, mudaram e se adaptaram enquanto as ciências filosóficas e teológicas se destacaram 
progressivamente delas. É isto que abre uma perspectiva rica no nosso entendimento da filosofia medieval.

Pensemos numa letra, qualquer letra, digamos " $\mathrm{x}$ ". Para nós hoje em dia, esta letra representa um símbolo escrito - a maioria de nós diria provavelmente um símbolo arbitrário - para um som usado na fonética da nossa língua. Pensariamos até em certos atributos quantitativos deste som, como a freqüência e a amplitude de suas vibrações, o volume do som e mesmo nos bits informáticos que constituem um " $x$ " nos nossos computadores. Nosso entendimento de uma letra seria dominado por uma interpretação quantitativa.

Agora, tentemos reproduzir, aproximadamente, a maneira pela qual um Agostinho, um João Escoto Erígena, ou um Boaventura, abordariam o mesmo assunto. $O$ que eles imaginariam, pensariam, refletindo na natureza de um " $x$ "? Antes de mais nada, eles viriam neste simbolo, simultaneamente e sem conflito de perspectivas, uma letra que representa um som e um número que representa uma soma. Parece que na maioria das línguas tradicionais, ou seja, pré-modernas, as letras serviram tanto para os sons de linguagem no tempo, quanto para os números e dimensões dos corpos no espaço. Qualidades e quantidades ficaram inter-relacionadas na grafia mesma da linguagem humana.

Gramma e arithmos, letra e número, qualidade e quantidade, nomes e medidas - alguns iam tão longe a ponto de identificar as artes triviais com as artes do céu (não sem referências à tríade das artes como manifestação da Santíssima Trindade) e as artes quadriviais com as da terra (a quaternidade sendo símbolo natural para a ordem material - as quatro direções, os quatro elementos, as quatro estações etc.). Esta observação nos conduz à seguinte reflexão.

Das doutrinas teológicas do pensador medieval, nenhuma o marcou tão profundamente quanto a da Incarnação da Segunda Pessoa da Santíssima Trindade em Jesus Cristo: Et Verbum caro factum est. Esta inesperada doutrina colocou diante da mente do cristão três fatos imprescindiveis da sua fé: 1) a vida, o ensinamento, a morte e a ressurreição de Cristo, o Verbo Encarnado, o falar mesmo de Deus entrado neste mundo - Cristo, como aquilo que Deus quis dizer a nós depois do pecado; 2) o mundo mesmo, na sua estrutura física e matemática, como aquilo que Deus quis dizer a nós antes do pecado, porque "todas a coisas foram feitas por ele [o Logos], e sem ele nada foi feito" (João 1:3), e "nele [no Logos] foram criadas todas as coisas nos céus e na terra, as visiveis e as invisiveis [...] tudo foi criado por ele e para ele..." (Col. 1:16).

A doutrina cristã da criação pelo Logos implica um universo cheio de sentido, um certo prolongamento pela criação da mesma processão do Filho do Pai, em Deus, por geração; e enfim, 3) Deus precisamente como Trindade, entendendo por Deus alguém que fala, a Segunda Pessoa sendo o Verbo, a Expressão completa do Pai no Espirito Santo. Este último sentido do Verbo, o que Deus diz de Si Mesmo a Si Mesmo, fica reservado para os ouvidos das almas glorificadas, percebidas só imperfeitamente e esporadicamente pelos místicos nesta vida.

O ponto importante aqui é que as doutrinas-chave do cristianismo ensinam que tudo tem significado: o foco da fé cristã na pessoa e obra de Cristo, para este significado é que ambos, a Bíblia e o universo, são expressões do mesmo Logos, 
do mesmo Verbo, em duas vertentes complementares. E a harmonia entre estas duas expressões se radica na sua origem comum no Verbo que Deus diz de $\mathrm{Si}$ Mesmo a Si Mesmo.

Num sermão do século XIII, atribuído no passado a Tomás de Aquino, o homilista exprime um lugar comum sobre a relação entre a Bíblia e a Natureza: "Deus teve o cuidado de produzir para nós escritos excelentes, a fim de nos instruir em perfeição [...] Esses escritos encontram-se em dois livros: o livro da criação e o da Escritura. No primeiro, são tantas as criaturas quantos os escritos excelentes que nos ensinam a verdade sem mentira. E aí está por que Aristóteles, a quem perguntaram onde aprendera tanto e a tal ponto, respondeu: 'Nas coisas, que não sabem mentir"'.

Aqui achamos o motivo mais potente para a sistematização e esquematização das sete artes liberais nos dois grupos. Essas artes, herdadas dos gregos, apresentaram ao homem medieval os recursos para uma dupla alfabetização: pelo trivium, os meios necessários para ler a Sagrada Escritura, o livro de Deus ao mundo dos pecadores; e pelo quadrivium, os meios para ler o sentido e o simbolismo do mundo físico, o livro de Deus ao mundo já antes do pecado. O primeiro sentido da palavra artista, aquele que completou os seus estudos na Faculdade das Artes, era a pessoa que tinha aprendido a "ler" os dois livros: o livro da Bíblia e o livro da Natureza. Uma vez "letrado", ele podia passar para a Faculdade de Direito, a de Medicina, ou a de Teologia, para estudar os próprios assuntos apresentados nos dois livros.

\section{2-O Trivium}

As três artes de linguagem foram chamadas artes sermocinales (artes verbais) e governaram a maneira pela qual o homem enfrenta a realidade com o seu Logos, ou seja, a sua língua, as suas palavras. A prática mostra que nós experimentamos uma realidade já existente que nos esforçamos por nomear e descrever. Consideramos os nossos nomes e as nossas descrições adequadas na medida em que refletem a maneira de existir e de atuar das coisas mesmas. Este modo de existir foi por vezes chamado de modus essendi (o modo de ser) e foi tarefa da Gramática apanhar este modo de ser pela sua morfologia e a sua sintaxe.

Uma vez captando as coisas desta maneira rudimentar, a mente humana começa a pensar sobre o sentido das palavras e as suas inter-relações, comparando palavra com palavra, proposição com proposição e, finalmente, chegando a aprofundamentos do conhecimento através de inferências tiradas de certas proposições. Este aspecto do nosso encontro lingüístico com a realidade, esta elaboração interior pela razão dos dados da Gramática, este modus intelligendi (modo de entender) foi governado pela arte da Dialética (mais ou menos coincidente com o que chamamos hoje de Lógica).

Enfrentando as coisas com a Gramática, ponderando as coisas com a Lógica, o homem sente mais uma necessidade, uma necessidade imposta por sua própria natureza humana. Ele tinha começado a sua inter-relação lingüística com o mundo empregando o órgão dentro da sua boca - o mesmo órgão com que ele acolhe o alimento, saboreando-o e passando-o para o corpo para sua assimilação. A Gra- 
mática é também um "comer" da realidade, um saborear das coisas antes de passá-las para a razão. E analogamente ao processo de digestão, em que o corpo trabalha e assimila as comidas, tirando nutrimento delas, que a língua mesma não podia tirar, a razão também trabalha e assimila os conceitos e juizos que a Gramática presta, assimilando a realidade, por assim dizer, ao "organismo" do intelecto humano.

Ora, o próximo passo é evidente. O corpo não se alimenta e não digere o alimento apenas para existir, mas também, e sobretudo, para atuar e agir. $\mathrm{O}$ alimento presta energia física que quer exprimir-se, articular-se para o mundo externo. O mesmo é o caso com o conhecimento que acolhemos (ou "comemos") pela Gramática, e elaboramos (ou "digerimos") pela Lógica. Este conhecimento quer também exprimir-se para fora, quer voltar ao mundo de que foi tirado. E como a força física anda do aparelho digestivo através dos nossos membros para exprimirse na locomoção, a força da linguagem passa do nosso intelecto para fora, voltando à mesma língua, para ser exprimida.

Mas notemos uma caraterística particular deste terceiro passo, seja no caso do processo biológico, seja no caso da linguagem: em ambos temos diante de nós um processo altamente adaptável, móvel, fluido mesmo. O que fazemos com a energia fornecida pelo alimento e elaborada pela digestão, fica indeterminado. Podemos fazer um passeio, jogar futebol, ou ficar sentados na poltrona e engordarmos. A digestão, em contraste, segue regras fixas e um itinerário predeterminado.

O mesmo é o caso com a linguagem. A Lógica tem regras estritas e um discurso predestinado - pelo menos para quem quer raciocinar com acerto e não sofrer aquela indigestão intelectual que chamamos de incoerência. Mas quando exprimimos o que sabemos, temos novos parâmetros que também requerem atenção: o ouvinte, as suas emoções, a sua situação, os seus preconceitos, etc. Quem quer não somente acolher a realidade gramaticalmente, entendê-la logicamente, mas também comunicar o seu conhecimento e as suas idéias eficazmente, precisa de mais uma arte. O modus communicandi (o modo de comunicar ou ensinar) exige a arte da Retórica.

Ora, estes três momentos do uso da linguagem foram aplicados ao estudo dos textos, sobretudo, claramente, do texto dos textos, a Bíblia, mas também dos clássicos gregos e romanos. Este exercício contemplativo da interpretação do texto da Bíblia segundo as três artes triviais passou por diversas fases de ênfase. Nos primeiros séculos da Idade Média, o interesse era talvez mais gramatical, na Alta Escolástica, mais lógico, e na transição ao tempo moderno, com o surgimento do humanismo renascentista, mais retórico. Mas estas simplificações ignoram a complexidade dos assuntos e dos autores dessas épocas. Certos Padres (Agostinho e Crisóstomo, por exemplo) estavam entre os mestres medievais da Homilética, uma filha cristã da Retórica clássica. E a Gramática especulativa, um movimento significativo de interpretação dos diversos modi significandi dos termos, gozou o seu tempo de ouro nos séculos XIII e XIV. 


\section{3- O Quadrivium}

Vou ater-me a uma apresentação ainda mais sumária das quatro artes matemáticas, por causa da sua complexidade e dos limites deste artigo. Algumas observações gerais, porém, bastariam para salientar o essencial.

Estas artes foram chamadas de artes reales, artes do real, quer dizer, não das palavras sobre o real, mas do real mesmo. O mesmo universo que nós acolhemos, elaboramos e exprimimos pelas artes verbais, enumeramos e medimos pelas artes reais. O "triângulo lingüístico" da Gramática, Lógica e Retórica se complementa pelo "quadrado matemático" de Aritmética, Geometria, Astronomia e Música.

$O$ universo em redor de nós exibe pelo menos três polaridades fundamentais: céu e terra (céu no sentido astronômico), números e extensões (ou na língua filosófica: quantidade discreta e quantidade contínua), e a maneira em que eles todos se movem ou não, ou seja, movimento e repouso. Ora, começamos com a Geometria, porque é sobre a terra que passamos a nossa vida. Esta terra precisa ser medida, para construir um santuário ou uma cidade, fixar os campos para Agricultura, fazer uma estrada, determinar fronteiras. Aqui temos a terra, as extensões matemáticas, em repouso.

Mas em cima, o Sol, a Lua e as estrelas todas giram em redor do nosso lar. Eles seguem cursos, se relacionam uns aos outros por ângulos e graus. Aqui temos o céu, as extensões em movimento. A nossa experiência do tempo se mede principalmente segundo estes movimentos: o nascer e o pôr do Sol, o mês (uma unidade basicamente lunar), $\mathrm{O}$ ano (uma unidade solar) e assim por diante. A quantidade contínua, no seu aspecto estático e dinâmico: eis o estudo da Geometria e Astronomia.

O mundo, porém, não consta unicamente de extensões, proporções e dimensões. Há coisas nele. Quantas? Começamos a contar, somar, multiplicar, etc. A Aritmética se apresenta: os números em repouso. Mas os números podem também mover-se. Números em movimento - eis a essência da Música: a escala musical, os intervalos, os modos do canto gregoriano e os tons de música moderna.

\section{4 - As artes liberais e a Filosofia}

Já desde os primeiros séculos, a Idade Média tinha conhecimento de Aristóteles, mas os escritos acessiveis eram pouquíssimos. Como é sabido, provavelmente poucos conheciam mais do que as suas primeiras duas obras lógicas, as Categonias e o Sobre a interpretação, e só referências oblíquas às outras. Ademais, Aristóteles mesmo não seguia o esquema das sete artes liberais, mesmo quando toda a sua obra foi levada em consideração. A Gramática ele pressupõe, mas não trata ex professo. A sua Retórica parece mais como uma extensão da sua Lógica, estudando a Retórica antes como uma forma de argumentação do que um estudo com o alcance enorme que ganhou em Cícero e Quintilião. E sobre Matemática, Aristóteles não escreveu praticamente nada. Para ele, as artes matemáticas têm em qualquer caso um valor totalmente subordinado às ciências físicas do real.

Sendo assim a sua postergação do régime quadrivial e trivial, um confronto com toda a largura e profundeza dos seus tratados sistemáticos, como aconteceu 
só nos séculos XII e XIII, graças às traduções secundárias do Árabe, e finalmente do próprio Grego, só podia significar um desafio bastante ameaçador para a pedagogia tradicional das sete artes liberais.

As primeiras reações das autoridades universitárias a este sistema aparentemente completo e abrangente de Filosofia eram, como sabemos, em grande parte negativas. Diversas condenações da parte das universidades nas primeiras décadas do século XIII pareciam ameaçar o aristotelismo com a anatematização. Mas precisamente o teor de respeito diante da verdade objetiva, que as próprias artes liberais tinham cultivado, gerava uma abertura intelectual entre os professores e alunos, que garantia por fim um acolhimento generoso ao corpus anistotelicum (sem minimizar as controvérsias tenazes entre o aristotelismo e o agostinismo.

A única arte liberal que achou nas obras de Aristóteles um tratamento extensivo era a Lógica. Quando, nos meados do século XII, as Primeiras Analíticas e as Segundas Analiticas foram traduzidas, toda uma teoria da ciência se apresentava pela primeira vez à mente medieval, e a mera classificação e organização dum patrimônio dava lugar a uma intuição na própria natureza da ciência. A aprendizagem de uma série de artes para a leitura dos dois "livros" da Bíblia e da Natureza começou a ocupar uma posição cada vez mais relativizada em face da teoria aristotélica da natureza da Filosofia especulativa e prática. Aqui comparaceram a Filosofia da Natureza, a Psicologia, a Metafísica, a Ética, a Política, etc., cada uma assumindo a sua posição no currículo dos alunos.

Mesmo a Teologia, até então definida quase totalmente pela arte de glosar e comentar a Sagrada Escritura, de organizar em sententiae as opiniões dos Padres e de escrever homilias, assumiu ambições cada vez mais "cientificas" para sua interpretação da revelação sobrenatural.

Que vai ficar das artes liberais neste brave new world de ciência peripatética? A Faculdade das Artes vai continuar a chamar-se assim pelo resto da Idade Média. E mesmo no mundo moderno, a Faculdade das Artes e Ciências vai continuar, em muitas universidades contemporâneas, a tradição de prestar os recursos básicos de uma educação propedêutica, capacitando os alunos a "ler" as ciências especializadas da pós-graduaçäo.

A Gramática medieval continuou desenvolvendo-se independentemente dos debates universitários sobre aristotelismo e agostinismo. O próprio estudo humanista das linguas devia mais a esta tradição que seu desprezo do Latim medieval deixa enxergar. A Retórica desenvolveu-se no estudo das letras e de oratória no Renascimento. As artes matemáticas começaram já no século XIV e XV a declarar a sua independência da Filosofia e das artes verbais, encaminhando os primórdios das modernas ciências da Natureza.

Sem a cultura intelectual gerada pelas artes liberais, a recepção de Aristóteles nas universidades medievais teria sido um processo bem mais problemático, e por causa precisamente de um analfabetismo quanto à leitura dos "dois livros" que, na História da Filosofia medieval, prepararam o homem a ver sentido e razão na sua vida, e também ordem e racionalidade no mundo que o cercava. Sem dúvida, nós continuamos lendo o livro da Natureza hoje, mas com os novos óculos de uma ciência cada vez mais subordinada às exigências inconstantes da tecnologia. $\mathrm{E}$ as 
artes verbais perdem-se facilmente em Filologia e cálculos logísticos. Um remédio para esta perda do espirito "sinóptico" (para falar com Platão) seria a volta a uma leitura (esta vez literalmente falando!) dos livros da nossa tradição grego-romana e judaico-cristã. Sem a orientação intelectual oferecida por estes clássicos seminais, ao texto da nossa leitura da realidade, vai faltar freqüentemente, e às vezes tragicamente, o contexto. 